DOI: $10.2478 / \mathrm{v} .10169-010-0001-1$

\title{
THE DUCTILE BEHAVIOR OF HIGH PERFORMANCE CONCRETE IN COMPRESSION
}

\author{
A. P. FANTILLI ${ }^{1}$, H. MIHASHI ${ }^{2}$, P. VALLINI $^{3}$, B.CHIAIA ${ }^{4}$
}

\begin{abstract}
The ductility of High Performance Concrete (HPC) can develop both in tension and compression. This aspect is evidenced in the present paper by measuring the mechanical response of normal vibrated concrete (NC), self-compacting concrete (SC) and some HPCs cylindrical specimens under uniaxial and triaxial compression. The post-peak behaviour of these specimens is defined by a non-dimensional function that relates the inelastic displacement and the relative stress during softening. Both for NC and SC, the increase of the fracture toughness with the confinement stress is observed. Conversely, all the tested HPCs, even in absence of confinement, show practically the same ductility measured in normal and self-compacting concretes with a confining pressure. Thus, the presence of HPC in compressed columns is itself sufficient to create a sort of active distributed confinement.
\end{abstract}

Key words: High performance concrete, Self-compacting concrete, Normal vibrated concrete, Confining pressure, Triaxial tests, Fracture toughness.

\section{INTRODUCTION}

Several reinforced concrete $(\mathrm{RC})$ structures fail via concrete crushing in compressed zones. This is the case, for instance, of over-reinforced concrete beams, like those reported in Fig.1a and tested in four point bending by Mansur et al. [1]. When fiber-reinforced, the post-peak behaviour of such members (Fig.1c) is remarkably more ductile than that observed in beams having the same geometry, the same steel rebars, and the same bearing capacities, but made of normal vibrated concrete (NC) without fibers (Fig.1c).

${ }^{1}$ Corresponding Author, Assistant Professor, Department of Structural and Geotechnical Engineering, Politecnico di Torino, Corso Duca degli Abruzzi, 24-10129 Torino, Italy, e-mail: alessandro.fantilli@polito.it

${ }^{2}$ Professor, Department of Architecture and Building Science, Tohoku University, Sendai, Japan, e-mail: mihashi@timos.str.archi.tohoku.ac.jp

${ }^{3}$ Professor, Department of Structural and Geotechnical Engineering, Politecnico di Torino, Torino, Italy, e-mail: paolo.vallini@polito.it

${ }^{4}$ Professor, Department of Structural and Geotechnical Engineering, Politecnico di Torino, Torino, Italy, e-mail: bernardino.chiaia@polito.it 
Thus, when crushing occurs, the type of concrete controls both the mechanical response and the ductility of RC structures.

The experimental campaign conducted by Кнаунт et al. [2] on highly confined RC columns, subject to concentric compression, also confirms the influence of the cement-based composites on the structural performances. More precisely, for a given cross-section, the load $v s$. average axial strain diagrams appear more ductile in the case of columns made of self-compacting concrete (SC) than in NC columns. These experimental observations can be usefully applied to designing $\mathrm{RC}$ compressed columns in seismic regions.
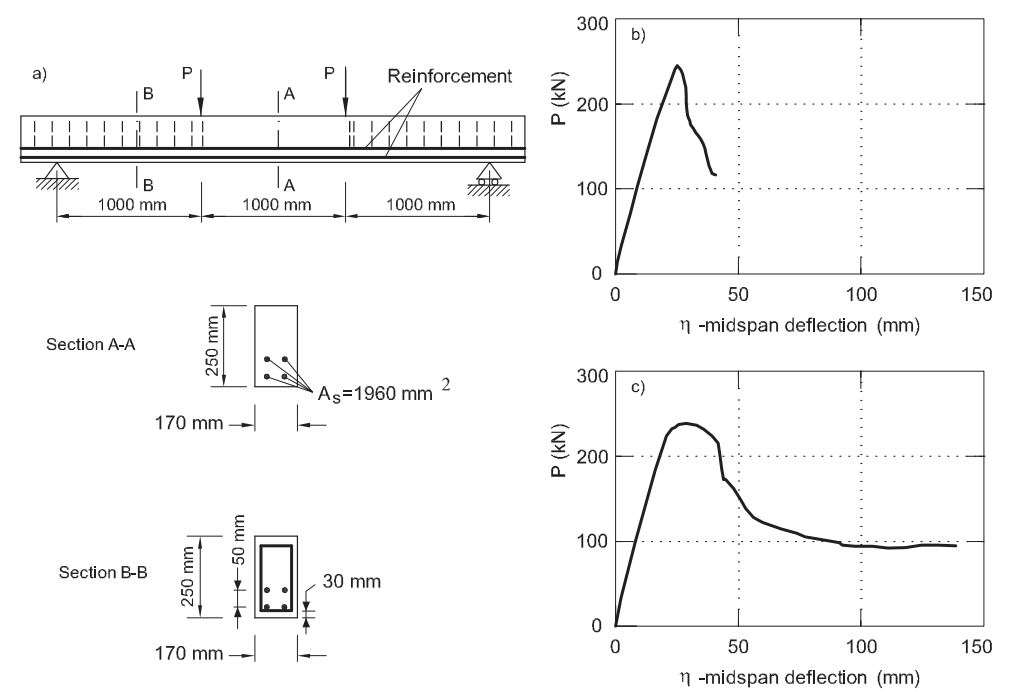

Fig. 1. The tests performed by Mansur et al. [1]: a) geometrical properties of beams tested in four point bending; b) mechanical response of plain RC beam; c) mechanical response of fiber-reinforced RC beam.

According to Eurocode 8 [3], if a required ductility cannot be attained because concrete strains are larger than $0.35 \%$, a compensation for the loss of resistance due to crushing can be achieved by means of an adequate confinement. Such a confinement, usually provided by transversal steel reinforcement (i.e., stirrups), and indicated by the confining pressure $\sigma_{3}$ (Fig. 2), allows designers to consider a more ductile stress strain $\left(\sigma_{c}-\varepsilon_{c}\right)$ relationship in compression. For instance, Fig. 2 shows the so-called parabola-rectangle diagrams proposed by Eurocode 2 [4] for confined and unconfined concretes.

Short steel fibers randomly dispersed in a cement-based matrix can generate confining pressures comparable with that of stirrups. The experimental campaign of GANESAN and Ramana Murthy [5], performed on short confined columns with and without fibers (Fig.3a), investigates on this aspect. As shown in Fig. 3b, the applied load- average strain $\left(P-\varepsilon_{c m}\right)$ diagram of RC columns, made with ordinary concrete and a transversal 

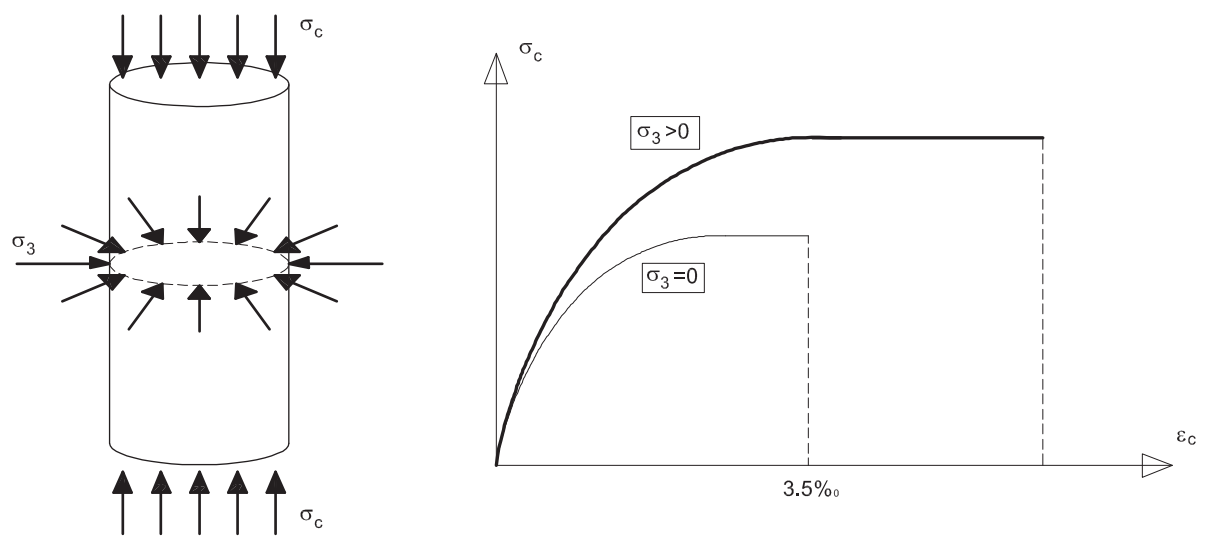

Fig. 2. The stress-strain relationship of compressed concrete with and without confinement [4].

reinforcement percentage equal to $\rho_{s}=1.6 \%$, is more or less similar (in terms of strength and ductility) to that of fiber-reinforced (FRC) columns, made with a reduced quantity of stirrups $\left(\rho_{s}=0.6 \%\right)$ and FRC (volume fraction $V_{f}=1.5 \%$, aspect ratio $L / \Phi=70$ ). Although fiber-reinforcements have been introduced in order to increase the ductility of cement-based composites in tension, they can also provide a sort of confinement, and therefore higher ductility in compression. For this reason, in High Performance Concretes (HPC) capable of reaching high tensile strains at failure, like the High Performance Fiber Reinforced Cementitious Composites (HPFRCC) tailored by Mihashi and co-workers [6], higher compressive fracture toughness should be expected. To confirm such a conjecture, the post-peak responses of different HPC under uniaxial and multi-axial compression are here investigated.
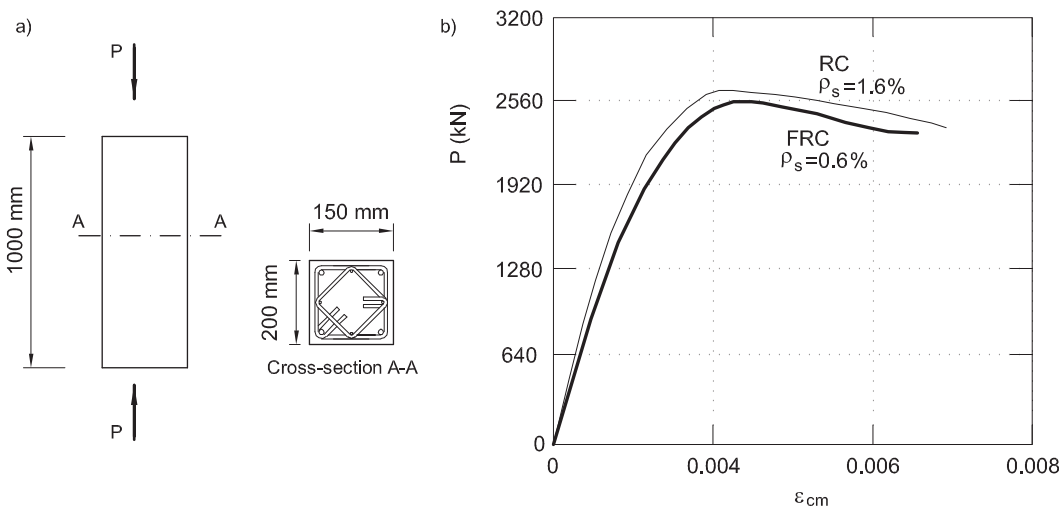

Fig. 3. The tests by Ganesan and Ramana Murthy [5]; a) geometry of the columns; b) load v.s. average strain curves. 


\section{Post-PEAK RESPONSE OF CONCRETE UNDER COMPRESSION}

The stress-strain relationships of concrete and quasi-brittle materials in compression can be divided into two parts (Fig. 4b). In the first part, when the stress is lower than the strength $f_{c}$ (and $\varepsilon_{c}<\varepsilon_{c 1}$ ), the specimen can be considered undamaged. In the case of plain concrete, the ascending branch of $\sigma_{c}-\varepsilon_{c}$ can be defined by the Sargin's relationship proposed by CEB-FIP Model Code [7]. As soon as the peak stress is reached, localized damage develops and strain softening begins. In this stage, the progressive sliding of two blocks of the cement-based material is evident. In Fig. 4a, the angle between the vertical axis of the specimen and the sliding surfaces is assumed to be $\alpha=18^{\circ}$. This value, as measured in many tests, can be also obtained through the Mohr-Coulomb failure criterion, if the tensile strength is assumed to be $1 / 10$ of the compression strength $\left(f_{c t}=0.1 f_{c}\right)$. The inelastic displacement $w$ of the specimen, and the consequent sliding $s$ of the blocks along the sliding surface, are the parameters governing the average post-peak compressive strain $\varepsilon_{c}$ of the specimen (Fig. 4).
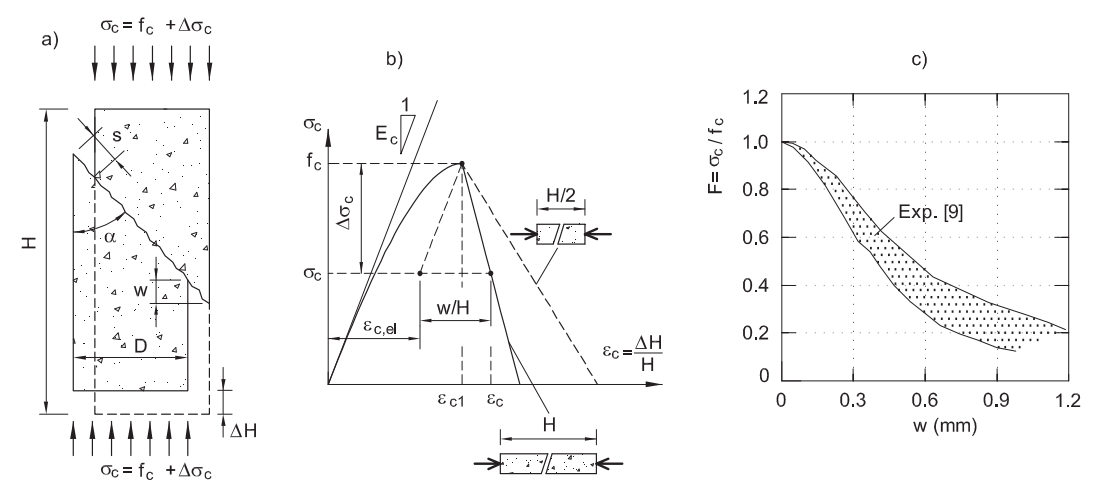

Fig. 4. The post-peak response of quasi-brittle materials in compression: a) sliding of the damaged specimen; b) possible stress-strain curves; c) the non-dimensional function $\mathrm{F}(\mathrm{w})$ measured by Jansen and Shah [9].

Referring to the specimen depicted in Fig.4a, post peak strains can be defined by the following equation [8]:

$$
\varepsilon_{c}=\varepsilon_{c, e l}+\frac{w}{H}=\varepsilon_{c 1}-\frac{\Delta \sigma_{c}}{E_{c}}+\frac{w}{H}
$$

where, $\varepsilon_{c 1}=$ strain at compressive strength $f_{c} ; \Delta \sigma_{c}=$ stress decrement after the peak; $H=$ height of the specimen (see Fig. 4b).

According to test measurements [8,9], the post-peak slope of $\sigma_{c}-\varepsilon_{c}$ increases in longer specimens (Fig. $4 \mathrm{~b}$ ), due to the $w / H$ ratio involved in the evaluation of $\varepsilon_{c}$ [Eq.(2.1)]. The stress decrement $\Delta \sigma_{c}$ can be defined as: 


$$
\Delta \sigma_{c}=f_{c}-\sigma_{c}=f_{c} \cdot[1-F(w)]
$$

where, $F(w)=$ non-dimensional function which relates the inelastic displacement $w$ and the relative stress $\sigma_{c} / f_{c}$ during softening (Fig. 4c); $f_{c}=$ compressive strength (assumed to be positive).

Substituting Eq.(2.2) into Eq.(2.1), it is possible to obtain a new equation for $\varepsilon_{c}$ :

$$
\varepsilon_{c}=\varepsilon_{c 1}-\frac{f_{c} \cdot[1-F(w)]}{E_{c}}+\frac{w}{H} \quad \text { for } \quad \varepsilon_{c}>\varepsilon_{c 1}
$$

Eq.(3), adopted for the post-peak stage of a generic cement-based material in compression, is based on the definition of $F(w)$, which has to be considered as a material property [8-9]. In all cement-based composites, this function should be evaluated experimentally on cylindrical specimens, as performed by Jansen and Shah [9] for plain concrete (Fig. 4c).

Fig. 5a shows the $F(w)$ relationships proposed by Fantilli et al. [10]. It consists of two parabolas and a constant branch:

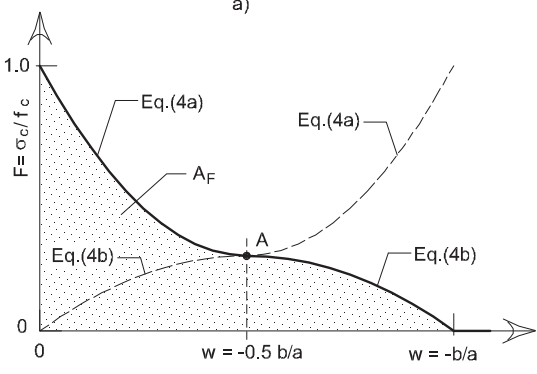

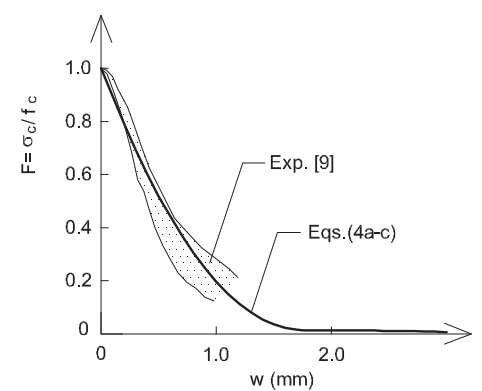

Fig. 5. Modelling the post-peak response under compression: a)The stress-inelastic displacement relationship proposed by Fantilli et al. [10]; b) the $F(w)$ relationship in the case of normal vibrated concrete.

$$
\begin{gathered}
F(w)=\frac{\sigma}{f_{c}}=1+a \cdot w^{2}+b \cdot w \quad \text { for } 0 \leq w \leq-\frac{b}{2 \cdot a} \\
F(w)=\frac{\sigma}{f_{c}}=-\left(1-\frac{b^{2}}{4 \cdot a}\right) \cdot\left(\frac{4 \cdot a^{2}}{b^{2}} w^{2}+\frac{4 \cdot a}{b} w\right) \quad \text { for } \quad-\frac{b}{2 \cdot a}<w \leq-\frac{b}{a}
\end{gathered}
$$




$$
F(w)=\frac{\sigma}{f_{c}}=0 \quad \text { for } \quad w>-\frac{b}{a}
$$

The parabolas are both defined by the same coefficients $a, b$ and have the same extreme point at $w=-0.5 b / a$, whereas $w=-b / a$ (i.e. twice the value at extreme point) is considered the maximum inelastic displacement corresponding to values of $F(w)$ larger than zero.

In the case of the plain concrete specimens, the values $a=0.320 \mathrm{~mm}^{-2}$ and $b=-1.12 \mathrm{~mm}^{-1}$ were obtained by means of the least square approximation of several tests [10]. As observed in Fig. 5b, the curves defined by Eqs.(2.4) fall within the range of the data experimentally measured by JANSEN and SHAH [9].

Analogously to concrete in tension, the area $A_{F}$ of the $F(w)$ curve (Fig. 4a) can be considered as proportional to the work of fracture in compression, and can be used to measure the compressive fracture toughness (i.e. the ductility) of concrete.

In the case of multi-axial compression, stress-inelastic displacement relationships, which should reproduce the confined post-peak stage, cannot be found in the existing literature. As is well known, two types of confinement, namely passive and active, can be produced. In compressed columns, passive confinements provided by transversal reinforcement (i.e., stirrups, tubes, strips, spirals, etc.), are only activated by concrete displacements. Thus, to define quantitatively this contribution, it is necessary to know the stress-transversal displacement relationship of concrete. Active confinement can be related to external stresses $\sigma_{3}$ applied by multi-axial compression on cubes in two or three directions, or by triaxial tests on cylinders (see the book by van Mier [8] for a review).

Only a single campaign of triaxial tests, performed by JAMET et al. [11] on micro-concrete, is reported in the current literature. In that case, the applied confinement was relatively high $\left(\sigma_{3}>3 \mathrm{MPa}\right)$, if compared to those produced by stirrups in ordinary RC columns. In accordance with Eurocode 2 [4], in columns under concentric compression, transverse reinforcement can develop about $\sigma_{3}=1 \mathrm{MPa}$ [12]. Consequently, with the aim of analyzing the equivalent confing pressures produced by high-performance concretes, the comparison between the results of new triaxial tests on NC and SC cylinders and the mechanical response of HPFRCC under uniaxial compression are reported.

\section{EXPERIMENTAL PROGRAM}

The post-peak behaviour of cement-based composites under multi-axial compression has been investigated at the Department of Structural and Geotechnical Engineering of Politecnico di Torino by means of triaxial tests on concrete cylinders (Fig. 6a). The experimental equipment, named HTPA (High Pressure Triaxial Apparatus) and 
described by ChIAIA et al. [13], is generally used to test cylindrical specimens made of soft rocks.

Each triaxial test consists of two stages. A specimen is initially loaded with a hydrostatic pressure $\sigma_{3}$ (Fig. 6b), then deviatoric loads $P$ are applied along the longitudinal direction with a velocity of $0.037 \mathrm{~mm}$ per minute (Fig. 6c). During the second stage of loading, the confining pressure $\sigma_{3}=$ const. is applied to the lateral surface, whereas the longitudinal nominal stress $\sigma_{c}$ becomes:
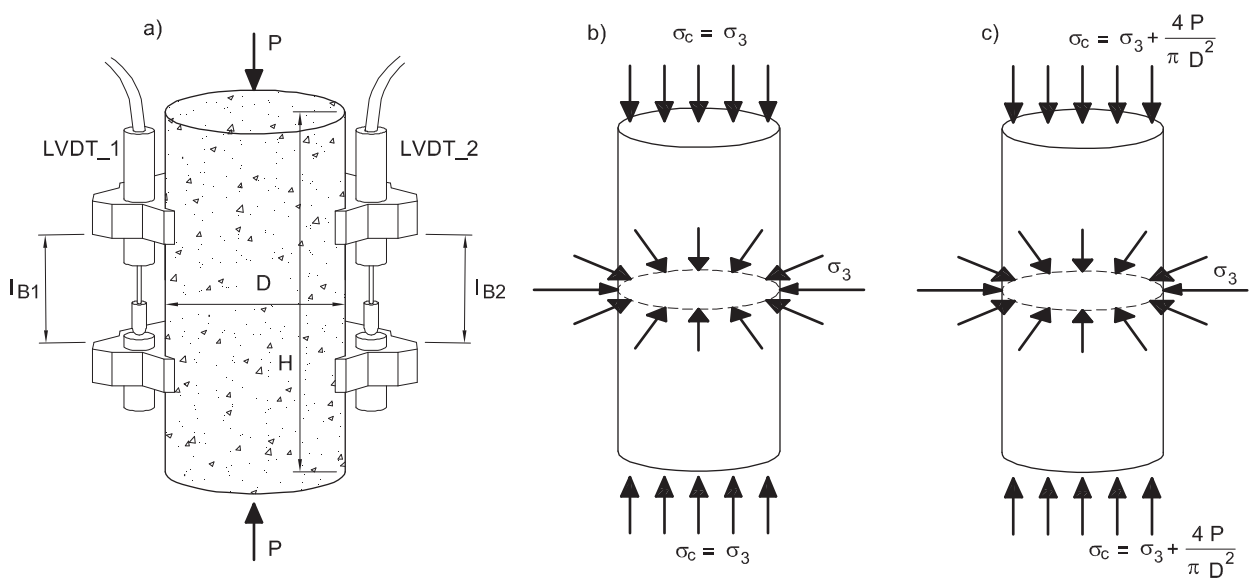

Fig. 6. Triaxial tests performed at Politecnico di Torino (Italy): a) position of the LVDTs; b) first stage of loading; c) second stage of loading.

$$
\sigma_{c}=\sigma_{3}+\frac{4 P}{\pi D^{2}}
$$

where, $P=$ applied deviatoric load; $D=$ diameter of the cross-section. Through a couple of LVDT, local longitudinal displacements and nominal longitudinal strains $\varepsilon_{c}$, are also measured (Fig. 6a).

Two values of confining pressure, namely $\sigma_{3}=0 \mathrm{MPa}$ and $\sigma_{3}=1 \mathrm{MPa}$ (reached in 10 minutes), are applied to the specimens. During the application of hydrostatic loads (Fig. 6b), stress increments are electronically recorded every 10 seconds. Similarly, in the second stage, when $\sigma_{3}=$ const . and $P$ increases, the values of deviatoric load, the relative displacement between the specimen's ends, and the longitudinal displacement along the lateral surface (taken by the LVDTs of Fig. 6a) are measured.

As the type of concrete (plain or fiber-reinforced, normal vibrated or self-consolidating) rules the mechanical response of $\mathrm{RC}$ structures, three types of self-consolidating concrete (SC-mix1, SC-mix2, and SC-mix3) and a single ordinary concrete (NC) were tested. Their compositions are reported in Table 1. Specifically, the self-consolidating concretes SC-mix1 and SC-mix2 have the same unit weight, but different amounts 
of aggregates. With respect to SC-mix1, in a cube meter of SC-mix2 the content of carbonate filler was increased by $50 \mathrm{~kg}$ and, contemporarily, the amount of coarse aggregate was reduced by the same quantity. Dramix RC 65/35 BN steel fibers (length $L=35 \mathrm{~mm}$, diameter $\Phi=0.55 \mathrm{~mm}$ ) having hooked ends were added to SC-mix3 (which is made of the same components of SC-mix2) in the proportion of $70 \mathrm{~kg} / \mathrm{m}^{3}$ (volume fraction $V_{f}=0.9 \%$, reinforced index $R I=57.6 \%$ ). SC-mix2 has a greater workability than SC-mix1, because of the different content of coarse aggregate and carbonate filler. In this way, SC-mix 3 (made with SC-mix2 and steel fibers) and SC-mix1 have the same workability.

Composition of NC, SC-mix1, SC-mix2, SC-mix3, and HPFRCC.

Table 1

\begin{tabular}{|c|c|c|c|c|c|}
\hline & $\mathrm{NC}$ & SC-mix 1 & SC-mix 2 & SC-mix 3 & HPFRCC \\
\hline Component & $\mathrm{kg} / \mathrm{m} 3$ & $\mathrm{~kg} / \mathrm{m} 3$ & $\mathrm{~kg} / \mathrm{m} 3$ & $\mathrm{~kg} / \mathrm{m} 3$ & $\mathrm{~kg} / \mathrm{m} 3$ \\
\hline Water & 180 & 180 & 180 & 180 & 180 \\
\hline \multicolumn{6}{|l|}{ Superplasticizer } \\
\hline (Addiment Compactcrete 39/T100) & - & 4.5 & 4.5 & 4.5 & - \\
\hline \multicolumn{6}{|l|}{ Superplasticizer } \\
\hline (Addiment Compactcrete 39/T11) & 1.42 & - & - & - & - \\
\hline \multicolumn{6}{|l|}{ Superplasticizer } \\
\hline (RHEOBUILD8000Ss) & - & - & - & - & 3.67 \\
\hline \multicolumn{6}{|l|}{ Cement } \\
\hline (Buzzi Unicem II/A-LL42.5R) & 290 & 250 & 250 & 250 & - \\
\hline \multicolumn{6}{|l|}{ Cement } \\
\hline (Equiv. to ASTM Type III) & - & - & - & - & 346.94 \\
\hline \multicolumn{6}{|l|}{ Slica Fume } \\
\hline (Elkem Microsilica) & - & - & - & - & 61.22 \\
\hline \multicolumn{6}{|l|}{ Carbonate filler } \\
\hline (Nicem Carb VG1-2) & 0 & 330 & 380 & 380 & - \\
\hline \multicolumn{6}{|l|}{ Fine aggregate } \\
\hline (Silica Sand) & - & - & - & - & 183.67 \\
\hline Fine aggregate $(0-4 \mathrm{~mm})$ & 900 & 910 & 910 & 910 & - \\
\hline Coarse aggregate $(6.3-12 \mathrm{~mm})$ & 950 & 650 & 600 & 600 & - \\
\hline \multicolumn{6}{|l|}{ Steel fibers } \\
\hline$($ Dramix RC 65/35 BN) & - & - & - & 70 & - \\
\hline \multicolumn{6}{|l|}{ Steel fibers } \\
\hline (Steel Cord) & - & - & - & - & 31.36 \\
\hline \multicolumn{6}{|l|}{ Polyethylene } \\
\hline (Dyneema) & - & - & - & - & 3.88 \\
\hline
\end{tabular}


Regarding the high performance fiber-reinforced cementitious concrete, two specimens were tested, under uniaxial compression $\left(\sigma_{3}=0\right.$, Fig. 7), at the Department of Architecture and Building Science of Tohoku University (Japan). HPFRCC is a hybrid self-consolidating concrete, whose reinforcement consists of both polyethylene fibers and steel cords [6]. The composition of such innovative composite is shown in Table 1, where the volume fractions $V_{f}$ of polyethylene fibers (diameter $\Phi=12 \mu \mathrm{m}$ and length $L=6 \mathrm{~mm}$ ) and of steel cords (diameter $\Phi=0.33 \mathrm{~mm}$ and length $L=32 \mathrm{~mm}$ ) are also reported.

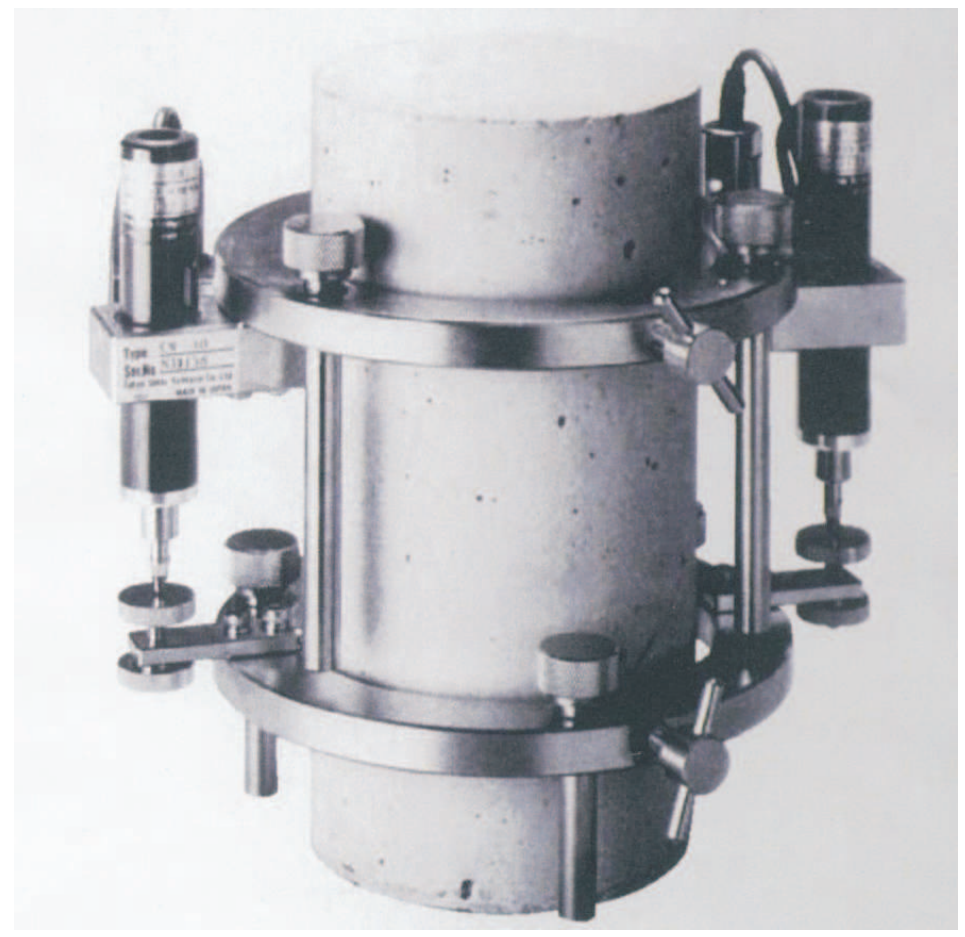

Fig. 7. Position of the LVDTs in the uniaxial tests performed at Tohoku University (Japan).

In order to obtain a low compressive strength in absence of confinement, the normal vibrated and the self-consolidating concretes have a low amount of cement. In this way, the failure stage can be observed also in the case of multiaxial compression. Conversely, due to the higher strength and to the reduced capacity of the loading machine, the failure of HPFRCC cannot be reached in presence of confining pressures. Hence, it was only tested under uniaxial compression.

The specimens of each concrete mixture were cast simultaneously in polystyrene form, then cured for one week under identical laboratory conditions, and finally tested after one month. Four couples of cylinders, with $H=140 \mathrm{~mm}$ and $D=70 \mathrm{~mm}$, were made of $\mathrm{NC}$ (NC0 and $\mathrm{NC} 1$ ), SC-mix1 (SC0 and SC1), SC-mix2 (SC0b and SC1b) 
and SC-mix3 (SCOc and SC1c). The two specimens of these couples were tested, respectively, at $\sigma_{3}=0 \mathrm{MPa}$ and $\sigma_{3}=1 \mathrm{MPa}$. Two HPFRCC cylinders, with $H=100$ $\mathrm{mm}$ and $D=50 \mathrm{~mm}$, were tested in uniaxial compression. The properties of each specimen are reported in Table 2.

Table 2

Mechanical and geometrical properties of the specimens tested in uniaxial and triaxial compression.

\begin{tabular}{|c|c|c|c|c|}
\hline Specimen & $\begin{array}{c}H \\
(\mathrm{~mm})\end{array}$ & $\begin{array}{c}D \\
(\mathrm{~mm})\end{array}$ & Type of concrete & $\begin{array}{c}\sigma_{3} \\
(\mathrm{MPa})\end{array}$ \\
\hline $\mathrm{NC} 0$ & 140 & 70 & $\mathrm{NC}$ & 0 \\
\hline $\mathrm{NC} 1$ & 140 & 70 & NC & 1 \\
\hline $\mathrm{SC} 0$ & 140 & 70 & SC-mix 1 & 0 \\
\hline $\mathrm{SC} 1$ & 140 & 70 & SC-mix 1 & 1 \\
\hline $\mathrm{SC} 0 \mathrm{~b}$ & 140 & 70 & SC-mix 2 & 0 \\
\hline $\mathrm{SC} 1 \mathrm{~b}$ & 140 & 70 & SC-mix 2 & 1 \\
\hline $\mathrm{SC} 0 \mathrm{c}$ & 140 & 70 & SC-mix 3 & 0 \\
\hline $\mathrm{SC} 1 \mathrm{c}$ & 140 & 70 & SC-mix 3 & 1 \\
\hline $\mathrm{HC} 0$ & 100 & 50 & HPFRCC & 0 \\
\hline $\mathrm{HC} 0 \mathrm{~b}$ & 100 & 50 & HPFRCC & 0 \\
\hline
\end{tabular}

\section{Test Results}

Figure 8 reports the stress-strain relationships obtained from the specimens made respectively with HPFRCC (Fig. 8a), normal concrete (Fig.8b), plain self-consolidating concrete (Fig. 8c), and fiber-reinforced self-consolidating concrete (Fig. 8d). In all cases, after the peak stress $f_{c}$, a remarkable strain softening branch can be observed in the $\sigma_{c}-\varepsilon_{c}$ diagrams. The highest compressive strength is achieved in the high-performance concrete. However, HPFRCC does not behave in a brittle manner under compression, as usually occurs in high-strength concrete specimens [12]. As a matter of fact, the post peak response of high performance concrete appears more ductile than $\mathrm{NC}$ and $\mathrm{SC}$.

If the confining pressure $\sigma_{3}$ increases (Figs. $8 \mathrm{~b}-8 \mathrm{c}$ ), or $70 \mathrm{~kg} / \mathrm{m}^{3}$ of steel fibers are added to SC (Fig. 8d), the post-peak response of NC and SC appears more ductile. The higher the confinement, the higher the values of $f_{c}$ and $\varepsilon_{c 1}$, reported, together with Young's modulus $E_{c}$, in Table 3.

By comparing all the post-peak branches reported in Fig. 8, it seems that the ductility of SC and NC specimens in the presence of $\sigma_{3}=1 \mathrm{MPa}$ is more or less the same of HPFRCC and fiber-reinforced self-consolidating concrete without any confinement. However, a direct comparison between the analyzed concretes is not possible in terms of nominal stress and strain, because specimens are different in length and have different nominal strengths. 

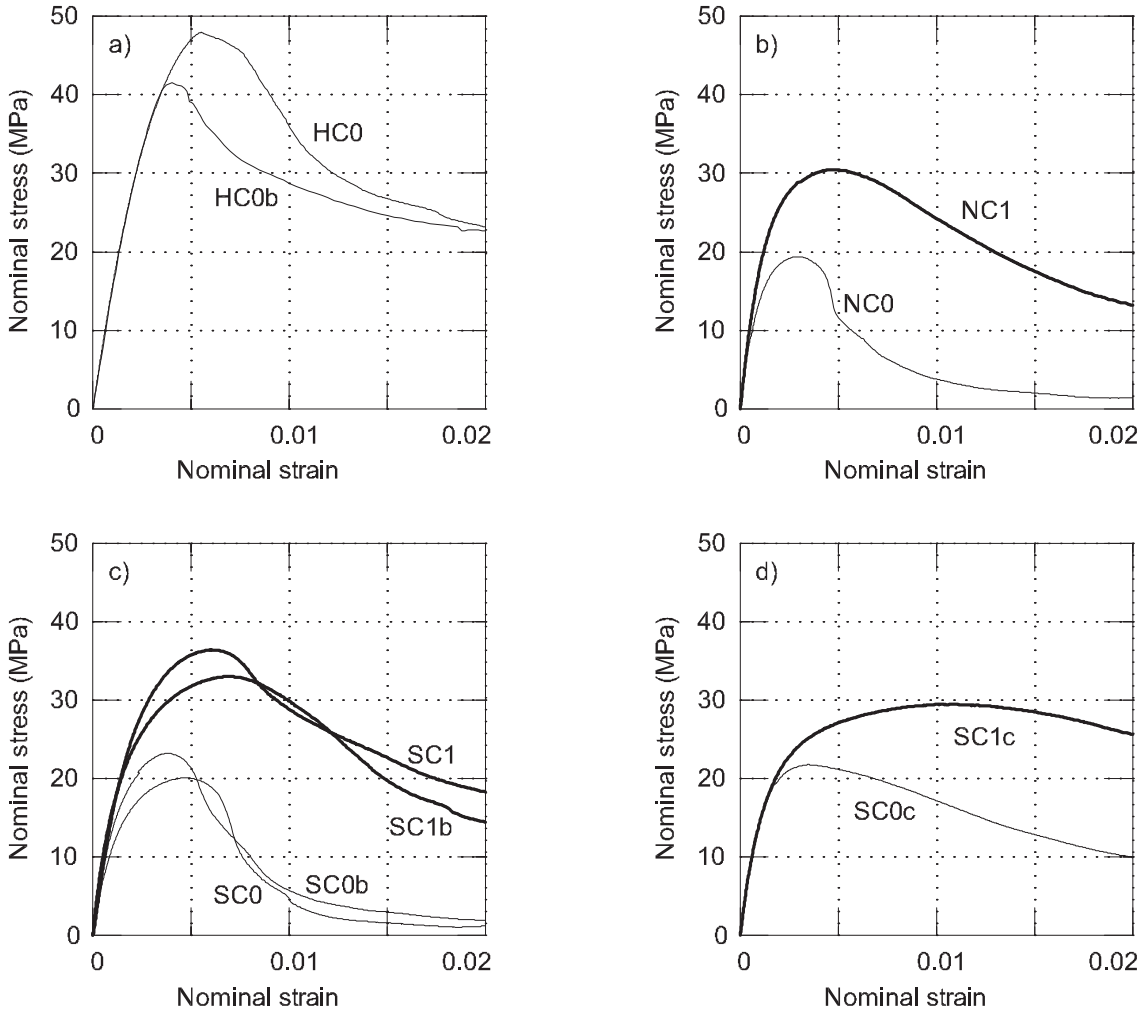

Fig. 8. The stress-strain curves resulting from triaxial tests: a) specimens made of HPFRCC; b) specimens made of NC; c) specimens made of SC-mix1 and SC-mix1; d) specimens made of SC-mix3.

Table 3

Mechanical properties measured in the tests.

\begin{tabular}{|c|c|c|c|}
\hline Specimen & $\begin{array}{c}f_{c} \\
(\mathrm{MPa})\end{array}$ & $\begin{array}{c}\varepsilon_{c 1} \\
(\%)\end{array}$ & $\begin{array}{c}E_{c} \\
(\mathrm{MPa})\end{array}$ \\
\hline $0 \mathrm{NC} 0$ & 19.4 & 0.293 & 24000 \\
\hline $0 \mathrm{NC} 1$ & 30.5 & 0.473 & 23000 \\
\hline $0 \mathrm{SC} 0$ & 20.1 & 0.479 & 17000 \\
\hline 0SC0b & 23.2 & 0.372 & 23000 \\
\hline 0SC1 & 36.4 & 0.604 & 19000 \\
\hline 0SC1b & 32.0 & 0.696 & 27000 \\
\hline 0SC0c & 21.8 & 0.352 & 18000 \\
\hline 0SC1c & 29.5 & 1.09 & 20000 \\
\hline HC0 & 48.0 & 0.551 & 16700 \\
\hline HC0b & 41.5 & 0.401 & 15100 \\
\hline
\end{tabular}




\subsection{POST-PEAK COMPARISON IN TERMS OF $F(w)$}

A more accurate comparison between the post-peak responses of HPFRCC, NC and SC under compression can be conducted in terms of $F(w)$ (Fig. 9). In particular, for a given $\varepsilon_{c}>\varepsilon_{c 1}$, the decrease of compressive stress $\Delta \sigma_{c}=f_{c}-\sigma_{c}$ (and $F=\sigma_{c} / f_{c}$ ) can be obtained through the $\sigma_{c}-\varepsilon_{c}$ diagrams experimentally evaluated (Fig. 8), whereas the corresponding $w$ (Fig. 4a) can be obtained from Eq.(3) $\left(f_{c}, \varepsilon_{c 1}, E_{c}\right.$ and $H$ are known from the tests).

The $F(w)$ curves reported in Fig. 9 are limited to $w=2 \mathrm{~mm}$, when compressive strains $\varepsilon_{c}$ are relatively large although, in some cases, stresses are larger than zero. However, in all the tests the relative stress $F=\sigma_{c} / f_{c}$ decreases with $w$.
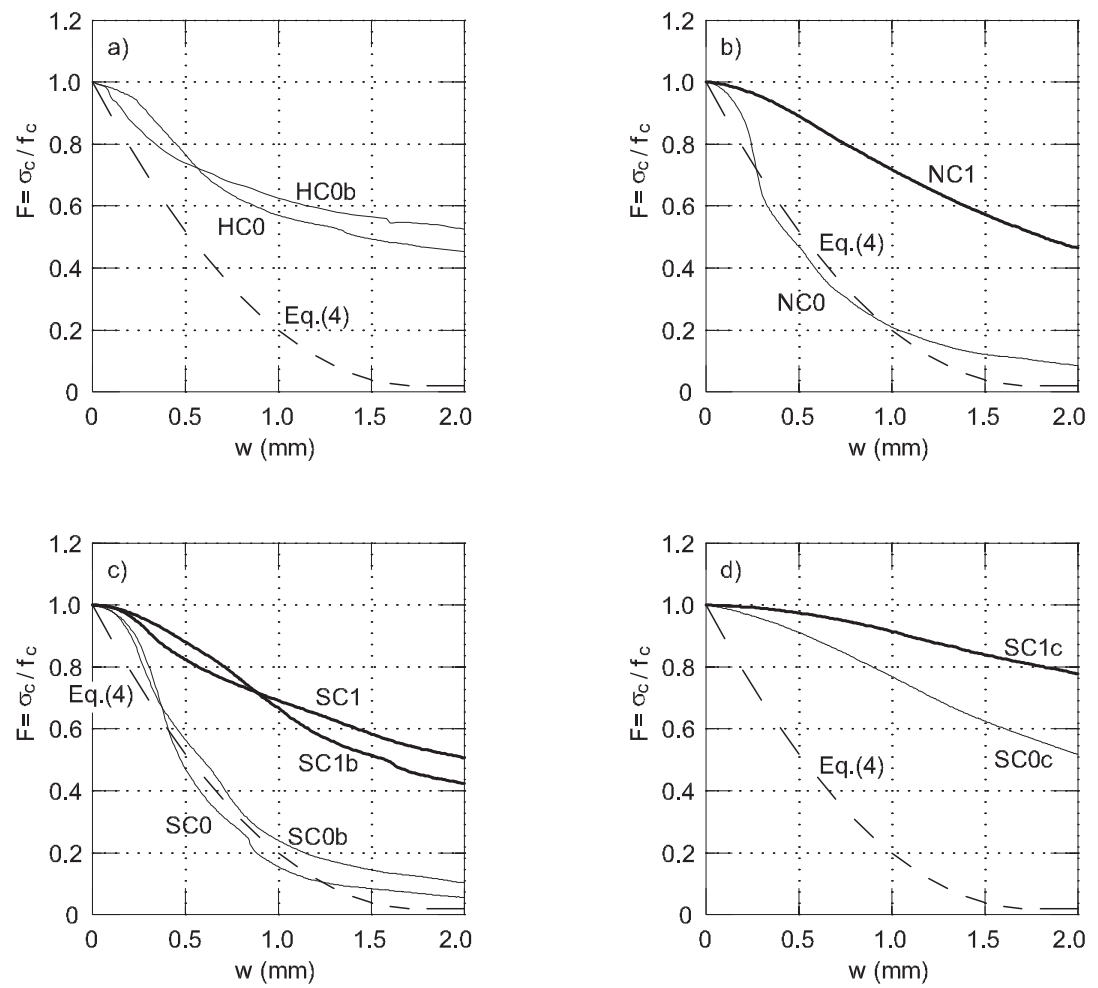

Fig. 9. The $F(w)$ curves resulting from triaxial tests: a) specimens made of HPFRCC; b) specimens made of NC; c) specimens made of SC-mix1 and SC-mix1; d) specimens made of SC-mix3.

The dashed curves reported in Fig. 9 represent the behaviour of NC and SC given by Eq.(4) in the case of zero confinement. As in the case of $\sigma_{3}=0$ the post-peak responses of the specimens $\mathrm{NCO}, \mathrm{SC} 0, \mathrm{SCOb}$ are correctly predicted by Eq.(4), and all the tests can be considered consistent [10]. Moreover, without fibers and confinement, 
the post-peak behaviour seems to be the same, independently of the workability of concrete.

Both for plain NC and SC, Fig.9b and Fig.9c show the increase of the compressive fracture toughness (within the range $w \sim 0-2 \mathrm{~mm}$ ) with the confining pressure $\sigma_{3}$. However, this phenomenon is also evident in the case of HPFRCC (Fig. 9a) and fiber-reinforced SC (Fig. 9d), which can show, in absence of confinement, more or less the same $F(w)$ obtained for NC and SC when $\sigma_{3}=1 \mathrm{MPa}$. Fig.10a shows the post-peak responses of the specimens $\mathrm{HCO}$ and $\mathrm{HCOb}$, which are closer to those of confined SC and $\mathrm{NC}$ (i.e., the range defined by $\mathrm{NC} 1, \mathrm{SC} 1, \mathrm{SC} 1 \mathrm{~b}$ ), than to the theoretical $F(w)$ obtained in absence of confinement [10] (the dashed line in Fig. 10a). The same mechanical response under compression can also be observed in the case of fiber-reinforced self-consolidating concrete (Fig. 10d), which can thus be considered a high performance concrete (HPC).
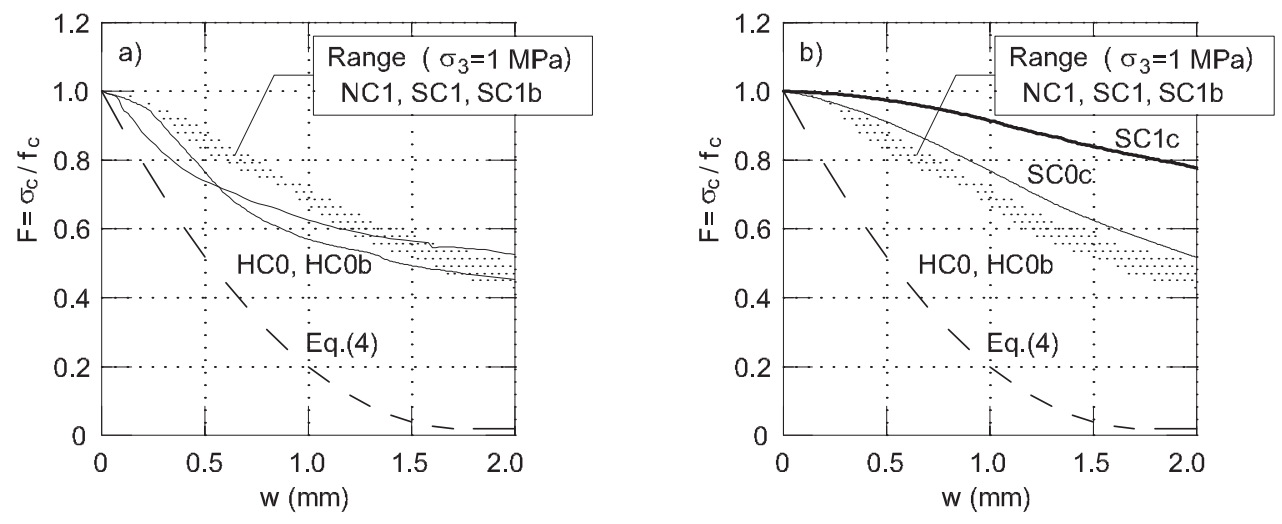

Fig. 10. The active confinement of high performance concretes: a) the $F(w)$ curves of HPFRCC; b) the $F(w)$ curves of SC-mix3.

Within the observed range ( $w \sim 0-2 \mathrm{~mm})$, compressive facture toughness of different concretes can be objectively measured by the area $A_{F}$ under the function $F(w)$ :

$$
A_{F}=\int_{0}^{2} F(w) d w
$$

In fact, since $F(w)$ is a relative stress normalized with respect to the compressive strength $f_{c}$, a comparison between all the cement-based composites, under uniaxial and multi-axial compression, is possible. Higher values of $A_{F}$ are attained in concretes capable of maintaining high loads after failure (i.e., in the case of ductile materials). Obviously, the maximum ductility $A_{F, \max }=2 \mathrm{~mm}$ is reached in the case of plastic behaviour $[F(w)=1=$ const. $]$. 
The areas $A_{F}$ computed by Eq.(4.1) for the tested specimens (Table 3) are also reported in the histogram of Fig. 11. In all cases, $A_{F}$ varies between $A_{F, \max }=2 \mathrm{~mm}$ and the lower limit $A_{F, \min }=0.61 \mathrm{~mm}$, corresponding to the normal and self-consolidating concrete without any confinement. To be more precise, $A_{F, \min }$ is obtained by substituting Eqs.(4) (with $a=0.320 \mathrm{~mm}^{-2}$ and $b=-1.12 \mathrm{~mm}^{-1}$ ) into Eq.(4.1). At $\sigma_{3}=1 \mathrm{MPa}$, for the specimens made of $\mathrm{SC}$ and $\mathrm{NC}$ (i.e., $\mathrm{NC1}, \mathrm{SC} 1, \mathrm{SC} 1 \mathrm{~b}$ ) the values of $A_{F}$ range between $1.39 \mathrm{~mm}$ and $1.46 \mathrm{~mm}$ (Fig. 11), and do not differ substantially from those measured for HPFRCC ( $\left.A_{F} \cong 1.31 \mathrm{~mm}\right)$ and fiber-reinforced self-consolidating concrete $\left(A_{F} \cong 1.53 \mathrm{~mm}\right)$ without confinement.

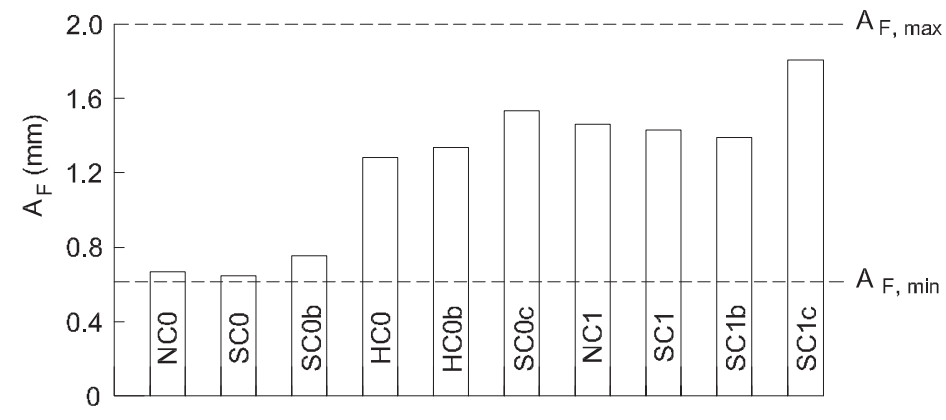

Fig. 11. The values of $A_{F}$ resulting from the tests.

\section{Conclusions}

From the results of an experimental campaign performed on NC, SC and HPFRCC cylinders under uniaxial and multi-axial compression, the following conclusions can be drawn:

- In normal and self-consolidating concrete, fracture toughness in compression increases in the presence of an active confinement.

- HPFRCC specimens, which show strain hardening in tension, provide a very ductile behaviour in compression, despite the higher strength.

- During the post-peak stage, the ductility of HPFRCC even in absence of confinement is comparable with that of NC or SC at $1 \mathrm{MPa}$ of confining pressure.

- Fiber-reinforced self-consolidating concrete behaves as a HPC under compression.

- The performance of fiber-reinforced composites can be quantified by the distributed confining pressure generated by the fibers.

From a practical point of view, in RC column, the higher compressive fracture toughness of HPFRCC is comparable with that of an active confinement. Thus, higher performance concretes can improve the ductility of compressed columns without increasing, and sometimes reducing, the amount of steel stirrups. As a result, the mechanical behaviour of concrete and, consequently, its durability and sustainability can 
be enhanced. However, further researches should be developed in order to introduce new self-consolidating concretes having a reduced amount of cement, but the same fracture toughness both in tension and compression.

The basic part of the present paper has been published and presented at the International Symposium BMC9 in Warsaw, October 2009 [14].

\section{REFERENCES}

1. M.A. Mansur, M.S. Chin, T.H. Wee, Flexural Behaviour of High-Strength Concrete beams, ACI Structural Journal, 94, 6, 663-674, 1997.

2. K.H. Khayat, P. Paultre, S. Tremblay, Structural Performance and In-Place Properties of Self-Consolidating Concrete Used for Casting Highly Reinforced Columns, ACI Materials Journal, 98, 1, 371-378, 2001.

3. UNI EN 1998-1:2005. Eurocodice 8 - Design of structures for earthquake resistance - Part 1: General rules, seismic actions and rules for buildings, pp.229.

4. UNI EN 1992-1-1:2005. Eurocodice 2 - Design of concrete structures - Part 1-1: General rules and rules for building, pp. 225.

5. N. Ganesan, J. V. Ramana Murthy, Strength and Behaviour of Confined Steel Fiber Reinforced Concrete Columns, ACI Materials Journal, 87, 3, 221-227, 1990.

6. A. Kawamata, H. Minashi, H. Fukuyama, Properties of Hybrid Fiber Reinforced Cement-based Composites, Journal of Advanced Concrete Technology, 1, 3, 283-290, 2003.

7. CEB (Comite Euro-International du Beton), "CEB-FIP Model Code 1990", bulletin d'information $\mathrm{n}^{\circ}$ 203-205, Thomas Telford, London, UK, 1993.

8. J. G. M. van Mier, Fracture Processes of Concrete: Assessment of Material Parameters for Fracture Models. CRC Press, 1996.

9. D. C. JANSEN, S. P. SHAH, Effect of length on compressive strain softening of concrete, ASCE Journal of Engineering Mechanics, 123, 1, 25-35, 1997.

10. A.P. Fantilli, H. Minashi, P. Vallini, Post-Peak Behaviour of Cement-Based Materials in Compression, ACI Materials Journal, 104, 5, 501-510, 2007.

11. P. Jamet, A. Millard, G. Nahas, Triaxial behaviour of a micro-concrete complete stress-strain curves for confining pressures ranging from 0 to $100 \mathrm{MPa}$, International conference on concrete under multiaxial conditions, 133-140, Toulouse 1984.

12. S.J. Foster, J. Liu, S.A. Sheikn, Cover Spalling in HSC Columns Loaded in Concentric Compression, ASCE Journal of Structural Engineering, 124, 12, 1431-1437, 1998.

13. B. Chiaia, A.P. Fantilli, P. Vallini, Post-peak response of confined SCC, In $3^{\text {rd }}$ North American Conference on the Design and Use of Self-Consolidating Concrete (SCC), Chicago 2008.

14. A. P. Fantilli, H. Mihashi, P. Vallini, B. Chiaia, The ductile behavior of HPFRCC in compression, In Ninth International Symposium on Brittle Matrix Composites BMC-9, Warsaw, October 2009.

\section{A B S T R A C T}

The ductility of High Performance Concrete (HPC) can develop both in tension and compression. This aspect is evidenced in the present paper by measuring the mechanical response of normal vibrated concrete (NC), self-compacting concrete (SC) and some HPCs cylindrical specimens under uniaxial and triaxial 
compression. The post-peak behaviour of these specimens is defined by a non-dimensional function that relates the inelastic displacement and the relative stress during softening. As a result, in normal and self-consolidating concrete, fracture toughness in compression increases in the presence of active confinement. Moreover, HPC specimens, which can also show strain hardening in tension, provide a very ductile behaviour even in absence of confinement. In particular, during the post-peak stage, the ductility of HPC is comparable with that of NC or SC at $1 \mathrm{MPa}$ of confining pressure. Moreover, the performance of fiber-reinforced composites can be quantified by the distributed confining pressure generated by the fibers. The presence of HPC in compressed columns is therefore sufficient to create a sort of active distributed confinement, and improve both the mechanical behaviour of concrete and its durability.

Remarks on the paper should be

Received January 15, 2010 sent to the Editorial Office

revised version

no later than June 30, 2010

March 10, 2010 